\title{
Registry-Based Incidence of Multiple Sclerosis in Southwestern Iran, 2001-2014
}

\author{
Khammarnia $\mathrm{M}^{1}$, Kassani $\mathrm{A}^{2}$, Izadi $\mathrm{E}^{3}$, Setoodehzadeh $\mathrm{F}^{4}$ \\ ${ }^{1}$ Health Promotion Research Center, Zahedan University of Medical Sciences, Zahedan, Iran \\ ${ }^{2}$ Departmetn of Community Medicine, School of Medicine, Dezful University of Medical Sciences, Dezful, Iran \\ ${ }^{3}$ Shiraz University of Medical Sciences, Shiraz, Iran \\ ${ }^{4}$ Department of Health Management and Economics, School of Public Health, \\ University of Medical Sciences, Tehran, Iran \\ e-mail:m_khammar1985@yahoo.com
}

\begin{abstract}
Multiple Sclerosis (MS) is the most common cause of neurological disability in young adults. It is estimated that more than two million people have MS worldwide. This study aimed to assess the incidence of MS and its associated factors in Shiraz, Southwestern Iran. Data related to the incidence of MS were obtained from the MS center of Shiraz University of Medical Sciences from 2001 to 2014. The study participants were all residents of Shiraz. The subjects were diagnosed with MS by neurologists (all newly diagnosed patients from 2001-2014) and were registered in MS center to receive treatment. Descriptive statistics and univariate and multivariate Poisson regression analysis were done. During the study period, 2637 eligible patients were identified. The highest incidence of MS occurred in 2011 and 2012 (17.62, 95\% CI: 8.02-38.72 and 16.92, 95\% CI: $6.23-45.88$ per 100,000 respectively). Besides, the female to male ratio was 2.95 and $44.71 \%$ of the MS patients (1070 cases) were in the 20-30 years' age group. In addition, the mean age of the patients was $30.18 \pm 8.86$ years. The results showed a significant difference among different age and sex groups regarding the incidence of MS $(p=0.01)$. Moreover, a significant relationship was observed between education level and incidence of MS ( $p=0.03)$. The incidence of MS has increased in the south of Iran more than other regions.
\end{abstract}

Keywords: Multiple sclerosis, Incidence, Young adults, Iran

\section{Introduction}

Multiple Sclerosis (MS) is a chronic inflammatory demyelinating disease of the central nervous system $^{1-3}$ with complex aetiology and still unknown causes, which affects individuals in their productive years. ${ }^{4} \mathrm{Up}$ to now, multiple putative aetiologic factors have been recognized for MS, but the main etiology of the disease has remained unknown. ${ }^{3}$

The mean age at onset of MS is 30 years (ranging from 20 to 40 years). In other words, the disease onset typically occurs in young adults, thus leading to long-term physical effects. ${ }^{5}$ This disease has also considerable social impacts and economic consequences. ${ }^{6,7}$ Individuals with MS can experience high levels of disability and impaired quality of life for prolonged periods. ${ }^{8}$
MS is recognized worldwide; however, the reported incidence and prevalence rates vary considerably among regions and populations. ${ }^{9}$ The observed patterns appear consistent with differential genetic predispositions and also implicate environmental risk factors that modulate the risk of MS at the population level. ${ }^{10}$ The highest prevalence of MS is related to Europe and North America. However, evidence has shown an increase in the incidence of this disease in arid regions and developing countries. ${ }^{11}$ The incidence of MS was 6.96/100,000 in Europe, ${ }^{12}$ 4.28/100,000 in France ${ }^{13}$ 11.2/100,000 in United Kingdom, ${ }^{14}$ and 9.1/100,000 in all regions of Iran in 2013. ${ }^{11}$ Several population-based studies have also shown a sharp increase in the prevalence and incidence of MS in Iran. ${ }^{11}$ Beside, a study in Iran showed that the incidence and prevalence of MS 
have increased rapidly, especially in females, in Iran. ${ }^{11} \mathrm{Up}$ to now, some studies have surveyed the incidence and prevalence of MS in Iran; however, this issue has not been investigated in south of the country. Shiraz, located in southwest of Iran, is one of the largest and most populous cities of the country. Nevertheless, no studies have been conducted on the incidence of MS in this area until now. Besides, a study conducted in Iran showed that future research should focus on determining the epidemiological features of MS in the neglected provinces, especially in south. ${ }^{11}$ Overall, it is important to have accurate and up to date information regarding the incidence of MS in Iranin order to understand the impact of this disease and to ensure that adequate resources are provided regionally for individuals affected by MS. ${ }^{8}$

Therefore, the present study aimed to assess the incidence of MS in Shiraz from 2001 to 2014. It is important for the health system and community to know about the epidemiological aspects of MS.. The study findings will present information about the disease trend, which can be used by health system managers for predicting services and planning for controlling and decreasing the disease incidence in the region.

\section{Methods and Materials}

The data related to MS patients were obtained from MS monitoring center of Shiraz University of Medical Sciences between 2001 and 2014.The MS monitoring center is the only institution, which delivers services to MS patients in south of Iran. Thus, most probably, all MS patients refer to this center for treatment follow-up. However, few patients may travel to other provinces for treatment.

Shiraz, located in southwest of Iran, is the fifth most populous city of Iran and the capital of Fars province with a population of over two million. This city is the patient referral centre in south of Iran. ${ }^{15}$ MS registry in Shiraz was run at the beginning of June 1995; therefore, this research included the patients who were diagnosed with MS between January 2001 and December 2014. A total of 2393 patients diagnosed with MS were enrolled in the study.

The inclusion criteria of this study were diagnosis of MS by neurologists, registry of residence address in the patients' records, and access to image-supported neurological diagnosis.

In order to calculate the incidence rate of MS in each year, the average population was obtained based on the census performed in Iran in 2006 and 2011 (Iran's statistical center). For other years, the average population was estimated by $\mathrm{N}_{\mathrm{t}}=\mathrm{N}_{0}(1+\mathrm{r})^{\mathrm{t}}(\mathrm{Nt}=$ population size at time $\mathrm{t} ; \mathrm{No}=$ original population size, $r=$ intrinsic rate of increase, and $\mathrm{t}=$ time). ${ }^{16}$

The data were analyzed using Excel (2013) and Stata-SE (version 11) software programs through descriptive statistics and univariate and multivariate Poisson regression. The association between each of the explanatory variables, including age, sex, and education level, and incidence rate of MS was determined using univariate and multivariate Poisson regression. Then, the final model of Poisson regression was fitted by all the factors that were statistically significant in the univariate analysis. The findings have been shown as incidence rates and $95 \%$ confidence intervals (CI $95 \%$ ). Besides, the significance level was set at 0.05 .

The research was conducted in accordance with the Helsinki Declaration and it was approved by the Ethics Committee of Shiraz University of Medical Sciences, Shiraz, Iran.

\section{Results}

This study was performed on 2393 MS patients with the mean age of $30.18 \pm 8.86$ years (CI 95\%: 30.16-30.88). Additionally, the mean age of male and female patients was $30.67 \pm 8.89$ (CI 95\%: 30.04-31.64) and 30.05 \pm 8.86 years (CI 95\%: 30.04-30.83), respectively. Also, approximately $78.81 \%$ of the MS patients $(n=1886)$ were female.

In all the MS patients, the important drugs prescribed based on physicians' orders were Cinnovex $(n=771,2.21 \%)$, Betaferon $(n=412,13.67 \%)$, Recigen $\quad(n=365,15.26 \%), \quad$ Rebif $\quad(n=327$, 13.67\%), and Avonex ( $\mathrm{n}=296,12.37 \%)$.Also, the lowest number of patients were treated with Zifron $(n=18,0.75 \%)$. The mean dose of the drugs used by the patients was $8.81 \pm 5.63$ dosages per month.

The highest incidence of MS was detected in 2011 (312 cases). Other characteristics of the patients and the relationships between their char- 
acteristics and the incidence of MS have been presented.

Table I: MS patients' characteristics and their relationship with the incidence of MS in Shiraz

\begin{tabular}{|c|c|c|c|c|c|}
\hline $\begin{array}{l}\text { Vari- } \\
\text { ables }\end{array}$ & $\begin{array}{l}\text { Classifi- } \\
\text { cation }\end{array}$ & $\begin{array}{c}\text { Frequency } \\
\text { (Percentage) }\end{array}$ & $\begin{array}{c}\text { Incidence } \\
\text { rate (per } \\
100,000)\end{array}$ & $\begin{array}{c}\text { CI } \\
95 \%\end{array}$ & $p$ \\
\hline \multirow{5}{*}{$\begin{array}{l}\text { Patients' } \\
\text { age (at the } \\
\text { time of } \\
\text { diagnosis) }\end{array}$} & $\begin{array}{c}\text { Lower } \\
\text { than } 20\end{array}$ & $296(12.37)$ & 7.25 & $\begin{array}{c}(5.12 \\
-\end{array}$ & \\
\hline & $20-30$ & $\begin{array}{c}1070(44 \\
.71)\end{array}$ & 10.25 & $\begin{array}{c}7.16) \\
(6.12 \\
-12 . \\
25)\end{array}$ & 0.01 \\
\hline & $30-40$ & $695(29.04)$ & 8.86 & $\begin{array}{l}5.12- \\
10.02\end{array}$ & \\
\hline & $40-50$ & $285(11.91)$ & 3.39 & $\begin{array}{c}2.22- \\
5.20\end{array}$ & \\
\hline & $\begin{array}{l}\text { Higher } \\
\text { than50 }\end{array}$ & $47(1.96)$ & 0.92 & $\begin{array}{c}0.22- \\
1.55\end{array}$ & \\
\hline \multirow[t]{2}{*}{ Sex } & Female & $\begin{array}{c}1886(78 . \\
81)\end{array}$ & 12.66 & $\begin{array}{l}9.66- \\
15.69\end{array}$ & 0.01 \\
\hline & Male & $507(21.19)$ & 6.81 & $\begin{array}{c}4.58- \\
8.21\end{array}$ & \\
\hline \multirow[t]{4}{*}{$\begin{array}{l}\text { Education } \\
\text { level }\end{array}$} & $\begin{array}{c}\text { Lower } \\
\text { than } \\
\text { Diploma }\end{array}$ & $617(27.34)$ & 6.25 & $\begin{array}{c}4.02- \\
8.36\end{array}$ & 0.03 \\
\hline & Diploma & $597(26.45)$ & 9.02 & $\begin{array}{l}6.23- \\
12.09\end{array}$ & \\
\hline & Academic & $\begin{array}{c}1043(46 . \\
21)\end{array}$ & 13.15 & $\begin{array}{l}9.98- \\
17.65\end{array}$ & \\
\hline & CIS & $693(29.02)$ & 9.25 & $\begin{array}{l}6.25- \\
14.58\end{array}$ & 0.02 \\
\hline \multirow[t]{4}{*}{ MS status } & $\begin{array}{l}\text { Relaps- } \\
\text { ing- } \\
\text { remitting }\end{array}$ & $\begin{array}{c}1431(59 \\
.92)\end{array}$ & 12.22 & $\begin{array}{l}8.58- \\
15.71\end{array}$ & \\
\hline & $\begin{array}{l}\text { Progressive- } \\
\text { relapsing }\end{array}$ & $112(4.69)$ & 5.22 & $\begin{array}{l}3.56- \\
7.25\end{array}$ & \\
\hline & $\begin{array}{c}\text { Primary } \\
\text { progressive }\end{array}$ & $48(2.01)$ & 1.23 & $\begin{array}{c}0.96- \\
2.09\end{array}$ & \\
\hline & $\begin{array}{l}\text { Secondary } \\
\text { progressive }\end{array}$ & $104(4.36)$ & 2.36 & $\begin{array}{l}1.10- \\
3.99\end{array}$ & \\
\hline
\end{tabular}

According to table I, the highest incidence of MS occurred in the 20-30 years' age group (1070 cases, $44.71 \%$ ), while the lowest incidence was detected in the above-50-years age group. Moreover, the finding of Poisson regression showed a significant difference among the age groups regarding the incidence of MS $(p=0.01)$. The results also revealed a significant difference between the males and females concerning the incidence of MS $(\mathrm{p}=0.01)$. Accordingly, the incidence rate of MS was attained as 12.66 and 6.81 per 100,000 in females and males respectively.

As shown in table I, most of the patients had academic education $(46.21 \%)$ followed by diploma $(26.45 \%)$. Besides, the incidence of MS was significantly associated with education level $(p=0.02)$; the highest incidence of MS (13.15) was related to the patients with academic education. Also, the most prevalent type of MS was the relapsing-remitting form (12.22).
The incidence rate of MS based on various years under study has been indicated in table II.

Table II: Incidence rate of MS in Shiraz in various years (20012014)

\begin{tabular}{ccccc}
\hline Year & $\begin{array}{c}\text { n } \\
\text { (Percentage) }\end{array}$ & $\begin{array}{c}\text { Population } \\
\text { average } \\
\text { (Shiraz) }\end{array}$ & $\begin{array}{c}\text { Incidence } \\
\text { rate (per } \\
\mathbf{1 0 0 , 0 0 0 )}\end{array}$ & CI95\% \\
\hline 2001 & $62(2.59)$ & 1576688 & 3.93 & $2.06-7.48$ \\
2002 & $61(2.55)$ & 1596525 & 3.82 & $1.48-9.83$ \\
2003 & $78(3.26)$ & 1616362 & 4.83 & $2.37-9.81$ \\
2004 & $91(3.80)$ & 1636199 & 5.56 & $1.18-26.12$ \\
2005 & $125(5.22)$ & 1656036 & 7.55 & $1.81-31.42$ \\
2006 & 106 & & & $3.54-11.27$ \\
& $(4.43)$ & 1675873 & 6.33 & \\
2007 & $170(7.10)$ & 1695481 & 10.03 & $3.55-28.34$ \\
2008 & $221(9.50)$ & 1715318 & 12.88 & $3.50-47.39$ \\
2009 & $161(6.73)$ & 1735387 & 9.28 & $3.87-22.21$ \\
2010 & 236 & & & $2.50-72.56$ \\
& $(9.86)$ & 1749926 & 13.49 & $8.02-38.72$ \\
2011 & 312 & 1770400 & 17.62 & $6.23-45.88$ \\
& $(13.04)$ & & & \\
2012 & 303 & 1791114 & 16.92 & $7.16-24.06$ \\
& $(12.66)$ & & & \\
2013 & 238 & 1812070 & 13.13 & $4.20-37.10$ \\
& $(9.95)$ & 1833271 & 12.49 & \\
2014 & 229 & & & \\
& $(9.57)$ & &
\end{tabular}

The average population was obtained based on the census performed in Iran in 2001, 2006 and 2011. For other years, it was estimated by $\mathrm{N}_{\mathrm{t}}=\mathrm{N}_{0}(1+\mathrm{r})^{\mathrm{t}}$.

According to table II, the highest incidence rate of MS was related to 2011(17.6292 per 100,000) and 2012 (16.92per 100,000). On the other hand, the lowest incidence rates were related to 20012006. The results showed a significant difference among the incidence rates of MS in the study years $(p=0.01)$. The trend of MS incidence based on sex has been presented in figure 1 .

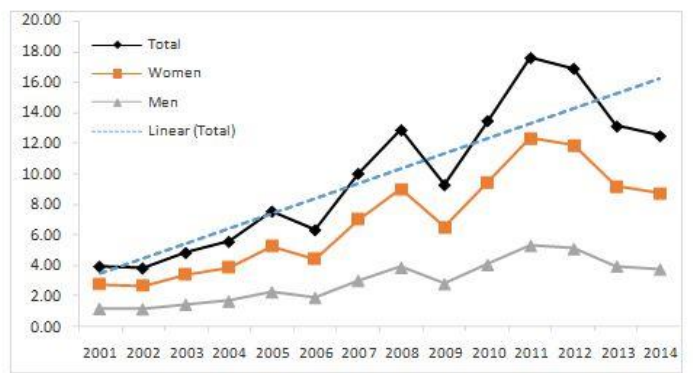

Figure 1: The incidence of MS in male, female, and total population in Shiraz in various years

Figure-1 shows that increasing trend of MS incidence in Shiraz from 2001 to 2014. Besides, this increasing trend was partly similar in male and female patients. However, the incidence rate of MS was quite higher in women than in men.

The association between the explanatory variables (age, sex, education level, and year) and 
incidence of MS using multivariate Poisson regression has been shown in table III.

Table III: Multivariate Poisson regression for the relationship between the explanatory factors and incidence of MS in Shiraz

\begin{tabular}{|c|c|c|c|c|c|}
\hline Variables & $\begin{array}{l}\text { Incidence } \\
\text { rate }\end{array}$ & SE & $\mathbf{Z}$ & $\begin{array}{c}p- \\
\text { value }\end{array}$ & $\begin{array}{c}\text { CI } \\
95 \%\end{array}$ \\
\hline $\begin{array}{l}\text { Patients' age (at } \\
\text { the time of } \\
\text { diagnosis) }\end{array}$ & 0.62 & 0.88 & 7.05 & 0.01 & $\begin{array}{l}0.08- \\
0.33\end{array}$ \\
\hline $\begin{array}{l}\text { Sex (fe- } \\
\text { male/male) }\end{array}$ & 2.95 & 0.95 & 3.37 & 0.01 & $\begin{array}{l}1.57- \\
5.55\end{array}$ \\
\hline $\begin{array}{l}\text { Education } \\
\text { level } 1 \text { (academ- } \\
\text { ic/under diplo- } \\
\text { ma) }\end{array}$ & 1.55 & 0.31 & 2.20 & 0.02 & $\begin{array}{l}1.04- \\
2.31\end{array}$ \\
\hline $\begin{array}{l}\text { Education } \\
\text { level } 2 \text { (diplo- } \\
\text { ma/under di- } \\
\text { ploma) }\end{array}$ & 1.44 & 0.58 & 0.92 & 0.35 & $\begin{array}{l}0.65- \\
3.17\end{array}$ \\
\hline Year & 1.07 & 0.11 & 6.71 & 0.01 & $\begin{array}{l}1.05- \\
1.09\end{array}$ \\
\hline
\end{tabular}

As shown in table III, in the multivariate model, age, sex, education level (academic/under diplo$\mathrm{ma}$ ), and year were significantly associated with the incidence of MS. However, no significant difference was observed between the patients with diploma and under diploma degrees regarding the incidence of MS ( $p=0.35)$. In addition, sex was the most important predictor of incidence of MS.

\section{Discussion}

Based on the present study results, the incidence rate of MS in Shiraz varied from 3.93 per 100,000 in 2001 to 17.62 per 100,000 in 2014. Besides, the highest rates were related to 2011 and 2012 (17.62 and 16.92per 100,000, respectively), which were higher compared to Europe (6.96 Enrique Alcalde-Cabero1), ${ }^{12}$ France (4.28), ${ }^{13}$ United Kingdom (11.2) ${ }^{14}$ Italy (6.4), ${ }^{17}$ Sweden (10.2) ${ }^{18}$ Norway (10.1 in 2009) ${ }^{19}$, and all regions of Iran (9.1 in 2013). ${ }^{11}$ Although the incidence of MS decreased in 2014, it was still higher compared to other regions in Iran and others countries. Overall, the study results showed that MS incidence had increased in the last decade, which is critical for Iran's health system. The increase in the incidence of MS in Shiraz might be due to the increase in MS patients' referral to this city. One study conducted in the center of Iran (Isfahan) indicated that MS incidence had approximately changed from 9.1 to 9.2 from 2009 to 2011. ${ }^{11}$ Besides, mortality has significantly increased in MS patients compared to the general population. ${ }^{20}$ Therefore, the incidence of MS is high in Shiraz, which is warning for Iran's health system. Thus, health managers should take this disease and its related aspects into account.

Ebrahimi found a negative association between the prevalence of MS and average environment temperature. Accordingly, the prevalence of the disease was lower in theareas with higher annual averagetemperature. ${ }^{21}$ However, the incidence of MS was higher in Shiraz withhot anddry weathercompared tonorth of Iran with cold weather. Moreover, Ching-Piao Tsai found that $54.03 \%$ of MS patients lived in north of Taiwan. ${ }^{22}$ Therefore, the results of our study were in contrast to those obtained by Ebrahimi.

In the current study, the female to male ratio was 2.95 and women comprised the majority of the MS patients in south of Iran. This finding has been confirmed in all the studies conducted in this field. Women accounted for $71 \%$ of the incident cases in UK. ${ }^{14}$ Besides, the crude female to male ratio was 2.26 in Sweden. ${ }^{18}$

Etemadifar found that the incidence and prevalence of MS increased rapidly, especially in females, in Iran. ${ }^{11}$ In north of Iran, $73.1 \%$ of the MS patients were female. ${ }^{7}$ In another study in Iran, the female to male ratio was $3.1 .^{21}$ The ratio was also reported to be 3.3 in Taiwan and Ita$l^{22,17}$ and 2.2 in Norway. ${ }^{19}$ Considering such high incidence rates in women, it is suggested to survey the gender-related factors to decrease and prevent MS in Iran. According to this study findings, female to male ratio has been stable over time. Benjaminsen also confirmed this result and found that the ratio remained unchanged from 1990. ${ }^{19}$ Other studies have also shown sex ratio stability over time. ${ }^{23,24}$ However, there has been an increase in this ratio across the world..$^{25,26}$

The findings of the present study demonstrated a simultaneous increase in population and MS incidence. The results also indicated that the highest incidence of MS was related to the 20-30 years' age group. However, a previous study showed that the peak incidence of MS occurred at the age of 40 years in women and 45 years in men in UK. ${ }^{14}$ Additionally, the mean age at MS diagnosis was 37.9 years in Taiwan. ${ }^{22}$ Also, the mean age of the patients was 33.4 years in north of Iran. ${ }^{7}$ This implies that age of MS morbidity has decreased in the twenty-first century and this 
distributional peak has shifted to the age group of 20-24 years. ${ }^{11}$ Since more than half of Iran's population are less than 35 years old, MS is a critical disease that threatens this age group, especially women. ${ }^{11}$

The results of the current study showed that most of the patients had academic degrees. This shows that educated women might be more exposed to MS compared to other women. It should be mentioned that 17.4 of the women in Iran have academic degrees. ${ }^{16}$ However, this variable has been investigated only in few studies. Two studies performed in Iran came to the same results as ours. ${ }^{27,28}$ However, Riise found a marked and linear inverse relationship between the level of education and the risk of MS in an oil company in Norway. ${ }^{29}$

According to the finding of the present study, the relapsing-remitting form of MS was detected in most of the patients $(59.60 \%)$. Another study in north of Iran also reported the relapsing-remitting form of the disease in $67.7 \%$ of the patients. ${ }^{7}$ Therefore, health workers should pay special attention to this form of the disease and investigate its causes to decrease and prevent MS relapse.

In Shiraz, most of the MS patients used Cinnovex as the dominant drug. In another study, most of the patients used beta-interferon for a period of at least fouryears. ${ }^{30}$ Hence, future studies are recommended to investigate the effectiveness of MS drugs in Iran.

\section{Conclusion}

The incidence of MS has rapidly risen in south of Iran compared to other regions. This incidence was similar to that reported in many western countries. Moreover, the incidence of MS in women was two folds higher than that in men, which is warning for Iran's health system. Therefore, future researches should focus on MS risk factors, especially in women, and strategies to decrease the incidence of the disease. It is also necessary to increase the awareness of health managers and health policymakers about the increasing risk of MS in Iranian population.

Acknowledgement: The authors would like to thank Ms. A. Keivanshekouh at the Research Improvement Center of Shiraz University of
Medical Sciences for improving the use of English in the manuscript.

Conflicts of interest: The authors declare that they have no conflicts of interest.

\section{References}

1. Moghaddam Tabrizi F, Moloud Radfar M. Fatigue, Sleep Quality, and Disability in Relation to Quality of Life in Multiple Sclerosis, Int J MS Care. 2015; 17(6): 268-74.

2. Tsai CP, Lee CT. Multiple sclerosis incidence associated with the soil lead and arsenic concentrations in Taiwan. PLoS One. 2013 ;8(6):e65911.

3. Pazokian M, Shanan M, Zakerimoghadam, Mehran A, Yekefallah L. The Comparative Effects of Stretching with Aerobic and Aerobic Exercises on Fatigue in Multiple Sclerosis Patients: A Randomized Controlled Clinical Trial. IJCBNM. 2013;1 (4): 230-37.

4. Frohman EM, Racke MK, Raine CS: Multiple sclerosis - the plaque and its pathogenesis. N Engl J Med . 2006; 354: 942-55.

5. PugliattiM1, Rosati G, Carton H, Riise T, Drulovic J, Vécsei L, et al. Theepidemiology of multiple sclerosis in Europe. Eur J Neurol . 2006; 13:700-22.

6. Marjaneh M. Fooladi. When Extreme Stress Reveals Multiple Sclerosis: A Case Report, IJCBNM .2013; 1 (1): 69-75.

7. Hashemilar M, Ouskui DS, Farhoudi M, Ayromlou H, Asadollahi A. Multiple sclerosis in East Azerbaijan, North West Iran, Neurology Asia 2011; 16 (2) :127- 31 .

8. Mackenzie IS, Morant SV, Bloomfield GA, MacDonald TM, O'Riordan J. Incidence and prevalence of multiple sclerosis in the UK 1990-2010: a descriptive study in the General Practice Research Database. J Neurol Neurosurg Psychiatry. 2014; 85(1):76-84.

9. Kingwell E, Marriott JJ, Jetté N, Pringsheim T, Makhani N, Morrow SA et al. Incidence and prevalence of multiple sclerosis in Europe: a systematic review. BMC Neurol. 2013; 13: 128.

10. Orton SM, Herrera BM, Yee IM, et al. Sex ratio of multiple sclerosis in Canada: a longitudinal study. Lancet Neurol. 2006; 5:932-36.

11. Etemadifar M, Sajjadi S, Nasr Z, FiroozeeiTS, AbtahiSH, Akbari Met al. Epidemiology of multiple sclerosis in Iran: a systematic review. Eur Neurol. 2013; 70 (5-6):356-63. 
12. Alcalde-Cabero E, Almazán-Isla J, García-Merino A, de Sá J, de Pedro-Cuesta J. Incidence of multiple sclerosis among European Economic Area populations, 1985-2009: the framework for monitoring. BMC Neurol. 2013; (12): 13-58.

13. Incidence of multiple sclerosis among European Economic Area populations, 1985-2009: the framework for monitoring. BMC Neurol. 2013; 13:58.

14. Yaouanq J, Tron I, Kerbrat A, Leray E, Hamonic S, Merienne $\mathrm{M}$ et al. Register-based incidence of multiple sclerosis in Brittany (north-western France), 2000-2001. J Acta Neurol Scand. 2015;131(5):321-8.

15. Khammarnia M, Kassani A, Amiresmaili MA, Sadeghi A, Zahra KarimiJaberi Z, Kavosi Z. Study of patients absconding behavior in a general hospital at southern region of Iran, Int J Health Policy Manag 2014, 4(3):137-41.

16. Mackenzie IS, MorantSV, Bloomfield GA, MacDonald TM, O'Riordan J. Incidence and prevalence of multiple sclerosis in the UK 1990-2010: a descriptive study in the General Practice Research Database. J Neurol Neurosurg Psychiatry. 2014; 85(1):76-84.

17. Incidence and prevalence of multiple sclerosis in the UK 1990-2010: a descriptive study in the General Practice Research Database. J Neurol Neurosurg Psychiatry. 2014;85(1):76-84.

18. Khammarnia M, Kassani A, Amiresmaili MA, Sadeghi A, Zahra KarimiJaberi Z, Kavosi Z. Study of patients absconding behavior in a general hospital at southern region of Iran, Int $\mathrm{J}$ Health Policy Manag. 2014; 4(3):137-41.

19 Estimation of Iranian population based on cities in 2010, Iran statistical center, 2010. (Accessed March, 2014, at https://www.amar.org.ir/.) [in Persian].

20 Nicoletti A1, Bruno E1, NaniaM1, Cicero E1, Messina S1, ChisariC1, etal. Multiple Sclerosis in the Mount Etna region: possible role of volcanogenic trace elements. PLoS One. 2013: 11; 8(12): e74259.

21. Ahlgren C, OdénA2, Lycke J. High nationwide incidence of multiple sclerosis in Sweden. PLoS One. 2014; 9(9): e108599.

22. Benjaminsen E, Olavsen J, Karlberg M, Alstadhaug KB. Multiple sclerosis in the far north - incidence and prevalence in Nordland County, Norway, 19702010. BMC Neurol. 2014; 14(1):226.
23. Scalfari A, KnappertzV, CutterG, Goodin DS, PGCE RA, Ebers GC. Mortality in patients with multiple sclerosis, Neurology. 2013; 81(2):184-92.

24. Ebrahimi HA, Sedighi B. Prevalence of multiple sclerosis and environmental factors in Kerman province, Iran, Neurology Asia. 2013; 18(4): 385 - 89.

25. Tsai CP1, Lee CT.Multiple sclerosis incidence associated with the soil lead and arsenic concentrations in Taiwan. PLoS One. 2013;8(6): e65911.

26. Taylor BV, Pearson JF, Clarke G, Mason DF, Abernethy DA, Willoughby E, et al..MS prevalence in New Zealand, an ethnically and latitudinally diverse country. MultScler . 2010; 16:1422-31.

27. Simpson S Jr, Pittas F, van der Mei I, Blizzard L, Ponsonby AL, Taylor B: Trends in the epidemiology of multiple sclerosis in Greater Hobart, Tasmania: 1951 to 2009. J Neurol Neurosurg Psychiatry. 2011; 82:180-87.

28. Trojano M, Lucchese G, Graziano G, Taylor BV, Simpson S Jr, Lepore V, et al. Geographical variations in sex ratio trends over time in multiple sclerosis. PLoS ONE. 2012; 7: e48078.

29. Orton SM, Herrera BM, Yee IM, Valdar W, Ramagopalan SV, Sadovnick AD, et al. Sex ratio of multiple sclerosis in Canada: a longitudinal study. Lancet Neurol.2006; 5:932-36.

30. Tavalol M, Yousefi S, Survey demographic characteristic of Multiple sclerosis patients inTehran, journal of Bio Ethics, 2014; 3 (8): 79-100 [in Persian]

31. Payamani F, Nazari AA, Noktehdan H, Ghadiriyan F, Karami K. Complementary Therapy in Patients with Multiple Sclerosis, Iran Journal of Nursing, 2012; 25 (77): 12-20 [in Persian]

32. Riise T, Kirkeleit J, Aarseth JH, Farbu E, Midgard $\mathrm{R}$, Mygland A, et al. Risk of MS is not associated with exposure to crude oil, but increases with low level of education. MultScler. 2011; 17(7):780-87.

33. Clarelli F, Liberatore G, Sorosina M, Osiceanu AM, Esposito F, Mascia E and et al. Pharmacogenetic study of long-term response to interferon- $\beta$ treatment in multiple sclerosis, Pharmacogenomics J. 2015: 85 